\title{
Negotiating Proximity in Sustainable Urban Planning: A Swedish Case
}

\author{
Ana Gil Solá * and Bertil Vilhelmson (D) \\ Unit for Human Geography, Department of Economy and Society, School of Business, Economics and Law, \\ University of Gothenburg, Gothenburg 40530, Sweden; bertil.vilhelmson@geography.gu.se \\ * Correspondence: ana.gilsola@geography.gu.se
}

Received: 22 November 2018; Accepted: 12 December 2018; Published: 21 December 2018

\begin{abstract}
In striving for sustainability, urban policy and planning increasingly emphasize proximity ideals in order to go beyond established mobility- and speed-oriented accessibility strategies. Yet proximity is a fluid concept with many contextualized meanings, cutting across most sectors of urban planning. When proximity is realized in actual planning, clarity and communicability are therefore required. Here we explored how urban planners in different fields of expertise understand and apply the proximity concept. Furthermore, we tested a collaborative tool enabling transparent discussion and fostering a joint basis for further application. Qualitative data were collected via six semi-structured, focus-group workshops with 35 planners of various competencies working in three western Swedish municipalities. The results indicated that planning goals of proximity were negotiated according to three understandings: One derived from the established understanding of transportation and land-use integration, relying on planners' expert views; a second emphasizing the local community understanding, highlighting the social context of neighborhoods; and a third comprising the personal environment understanding of the individual's closest physical space at a detailed scale level. Collaborative exercises resulted in the development of a communicative tool for negotiating perceived understandings of proximity, as well as planning goals.
\end{abstract}

Keywords: collaborative tool; planning; spatial proximity; sustainable accessibility; understanding; workshop method

\section{Introduction}

Proximity (or geographic nearness, propinquity) is an influential concept and a buzzword in current urban planning. Increased proximity is believed to enhance individuals' quality of life, boost neighborhoods, and promote environmental, social, and economic sustainability. The concept is central to discourse on how to reduce energy-consuming and polluting travel [1,2], foster local social ties, trust, and capital $[3,4]$, and promote economic activity and innovation [5,6]. Ideas of nearness lie at the heart of visions to revitalize and make cities vibrant and attractive via greater densification, land-use mixing and filling, and the co-location of various activities and facilities.

This proximity turn essentially represents an ongoing-or anticipated—shift in urban planning away from transport-dominated urban development $[7,8]$. Policy has shifted from viewing car transport as the ultimate norm and means by which citizens reach daily activities to more emphasis put on transport needs and reduced travel distance, local living, and the promotion of walking, cycling, and public transit [9-11]. Densification, land-use mixing, and slow mobility thus belong to a set of key notions in a redefined understanding of urbanity $[10,12-14]$ that goes beyond the established planning principles of 20th-century modernity [15], largely associated with speed, areal differentiation, energy-consuming transport, highway connectivity, and sprawl. Still, it must be remembered that mobility-based approaches de facto still dominate transportation planning in most countries [16-18]. 
In Sweden and other countries striving for sustainable development, the notion of proximity is prevalent in most contemporary urban policies. Among Sweden's three largest cities, Stockholm sells its vision of the urban future in terms of "A Closer City" [19], Gothenburg is branding itself the "Near Metropolitan" in a strategy to promote slower transport modes, public transport, and local living [20], while Malmö has started to evaluate accessibility improvement in terms of geographical distances between people and everyday activities [21]. In addition, medium-sized Swedish cities, in their comprehensive planning, define "the near city", "the compact city center", and "mixed land use" as leading goals for future development, stressing the importance of nearness in everyday life for all citizens (e.g., References [22,23]). Proximity-based thinking has become a typical example of policy mobility [24] (i.e., how elusive policy concepts travel between cities and regions, transmitted by consultants and stakeholders).

This proximity shift is associated with other important tendencies, needs, and challenges in current planning. One concerns recognizing the complexity of urban change and planning, and that measures, for example, SUMP-based guidelines within EU [25] require the involvement of various competences, professions, and stakeholders [26]. Establishing common ground, conceptual congruence, and beneficial communication between professions is necessary [27] and of immediate concern. Furthermore, shifts toward proximity thinking bring a focus on people rather than transportation modes and traffic flows, in order to take account of citizens' varied needs and activities in everyday life, involve citizens, and move from top-down expert forms to transparent and participatory forms of planning $[9,25,28]$.

When accomplishing such shifts in planning and practice, the specific meaning attributed to the concept of proximity becomes critical and contested. In detailing this understanding, we found a knowledge gap and a need to develop new and integrative planning practices emphasizing improved communication between professions, as well as between planners and citizens. This basic issue motivated our study. Drawing on a Swedish case, we aimed to investigate how one set of influential actors-local planners from different municipal-level sectors of expertise and responsibilityrecognizes, contextualizes, and implements the concept of proximity from a sustainability perspective. We concentrated on two interrelated research questions:

1. What understandings of proximity exist in current urban planning practice? We explored planners' perceived meanings and challenges regarding how spatial nearness is recognized and managed in different sectors of urban planning and administration.

2. How could a shared understanding of proximity be derived from various professional perspectives, conceptions, and interests? Through a collaborative process of organized workshops, we developed and discussed a tool to advance the development of proximity-oriented planning.

This study concentrated on urban planners, considering their performative roles as intermediate agents between policymakers, stakeholders, and citizens [29]. To explore the issues raised, we organized workshop discussions with planners from a wide range of urban sectors and responsibilities. Workshops were held in three cities-Gothenburg, Mölndal, and Uddevalla-in western Sweden. Our analysis drew on qualitative data derived from thematic group discussions as well as interactive tasks organized to stimulate responses.

Our case study adds to the scattered literature on planners' perceptions and emerging practices of advanced sustainable planning. This is relevant, because local planners' conceptions and emerging practices of proximity-oriented planning processes are poorly documented [14,30,31]. We also contribute by involving practitioners active in various municipal responsibilities, ranging from health and social care, school and child care, and leisure activities to energy, transport, the environment and green areas or parks, and comprehensive land-use planning. Caring for proximity in people's access to services is central to all these fields, not to be "owned" by one or a few of them, contrasting a role traditionally held by transportation and land-use planning departments.

The paper is organized as follows. The next section presents our analytical framework. Following this, we briefly describe the method and data, outlining the selection of cases and workshops. We then 
present the results, examining various understandings of proximity (i.e., differences in understanding engendered tensions in implementing proximity-led planning). The following section evaluates a heuristic tool usable as a basis for dialogue between planners and for deriving and communicating proximity needs in the population. A concluding discussion is presented in the final section.

\section{Analytical Framework}

\subsection{Proximity in Accessibility Planning}

Our study was based on the notion that geographic proximity-the location of people, services, and activities near one another-is one of several principal ways for people to access spatially distributed opportunities in the urban environment [32,33]. Accessibility is considered to be an umbrella term denoting an individual's potential to reach activities important to everyday life and well-being. Accessibility can also be enabled by mobility strategies, using fast means of travel, such as the car, or virtual strategies, using information and communication technologies to transcend space. These strategies can be implemented separately or in combination [28,33]. How and to what extent people choose physical mobility, proximity, or virtual strategies have important consequences for environmental and social sustainability. It is generally recognized that future urban development should rely more on proximity promotion in terms of densification, compactness, co-location, and mixed land use to combat sprawl and pollution and increase sustainability (e.g., References $[9,14])$.

A shift toward proximity-enhancing (i.e., distance reducing) strategies puts people's local access to a wide range of amenities important for quality of life-such as healthcare facilities, preschools and schools, social services, commercial services, leisure, cultural, and entertainment amenities, and parks and nature - at the center of planning $[34,35]$. It extends established accessibility planning beyond the conventional domains of transportation and land-use planning $[8,14,30,36]$, and reflects on the need for improved information systems, methods, and metrics that quickly map relevant bases for evaluation and decision-making [37-39]. Yet studies of urban planners' detailed understandings of accessibility in terms of proximity are rare [14,30,31]. One exception is that of Curl et al. [30], who examined how UK planners integrated accessibility policies in their local transport plans. They considered that improved accessibility in terms of proximity would enhance social inclusion, equality, and modal shifts. Non-car accessibility and proximate opportunities for underprivileged groups were in particular expected to improve. Outcomes were also seen to affect a wide range of sectors, particularly health, employment, and overall quality of life. Envall [40], also evaluating UK accessibility-based planning, concluded that it requires new planning skills and working methods. This was stressed by Haugen [34], who, in studying the importance of nearness, noted planners' need to recognize and prioritize what different groups of people want and need to access within easy reach in everyday life. Similarly, Boisjoly and El-Geneidy [37] investigated the design, benefits, and barriers to the use of proximity-based indicators among established land-use and transportation practitioners in the USA and Europe. Such indicators are intended to quantify the ease of reaching various activities or destinations using slow transportation modes, such as walking and biking, based on travel costs, distance, or time: For example, the number of jobs, retail stores, or parks reachable from a specific location within $10 \mathrm{~min}$ by walking. They found that lack of knowledge and data were the main barriers to using such methods in practice, rather than a lack of support and interest among regular urban planners.

A complementary view of the role of the proximate environment stresses the individual's functional capabilities. Wennberg et al. [41] and Hallgrimsdottir et al. [42], for example, examined how local planners in Sweden perceive and implement accessibility goals for public outdoor environments with regard to disabled people with walking difficulties. They found large variations in the applicable accessibility standards among Swedish municipalities, partly reflecting the degree of awareness revealed in local policy and planning.

Overall, according to the literature, the concept and role of proximity in accessibility planning appears ambiguous and contested, with the role of proximity in implementation varying between 
cases and contexts. This illustrates the critical and transformative role of planners in the transition to sustainable urban planning, which involves the mediation of new perspectives, methods, and fields of expertise in negotiations between various actors [29]. It calls for reflection on what is important for people to have nearby in their daily lives, and on who should answer this central question.

\subsection{The Role of Proximity in Social Sustainability}

Building on planning practices that put proximity at the center of accessibility planning, proximity can also be related to a wider context, not only as an individual tactic for accessing specific everyday life activities, but as important to issues of social inclusion, resident health, quality of life, and urban revitalization (i.e., values central to social sustainability) $[43,44]$. Unraveling social sustainability at the neighborhood scale, Dempsey et al. [43] discerned two central underlying concepts: Social equity and sustainability of community. Whereas the first relates to equity of access to key services, facilities, and transport infrastructure (see Section 2.1), sustainability of community highlights the importance of collective aspects of social life. It denotes the importance of local social interaction, participation in local community activities, community stability, pride and sense of place, and feeling safe and secure. For example, Leyden [45] analyzed the role of walkable neighborhoods, demonstrating that inhabitants of walkable, mixed-use neighborhoods were more likely to know their neighbors, participate politically, trust others, and be socially engaged than were people living in car-oriented suburbs. This was assumed to be due to the enhanced opportunities for resident interaction in neighborhood public areas, such as sidewalks, encouraging a sense of connection and familiarity. However, the relationship between urban form and social interaction in neighborhoods is also contested in the research $[43,46]$.

Associated with this is the understanding that residents' bonds to a place relate to their actual use of the area. If inhabitants feel attached to their neighborhood and experience it as positive, they are more likely to use local amenities in everyday life rather than traveling farther away [47]. Equally, local understandings and emotional ties are reinforced in places where people spend most of their time in everyday life $[48,49]$. Understanding a place therefore entails more than just examining the physical environment: It also entails considering social ties and memories as important aspects, meaning that places are understood differently by different people [48].

\subsection{Evolution of Proximity Policy}

Our study starts from the understanding that proximity policy is complex and works at different administrative levels. It involves different paradigms and professional understandings existing side by side within the same institutions [50]. It may contain conflicting goals [51,52]: For example, although current goals of sustainable development, such as reduced emissions, are clearly expressed and defined, they often conflict with stated (or tacit) goals of the continued dominance of car-based mobility and access [26]. Such goal conflicts can be explained by policy being complex and subject to continuous evolution. Importantly, policies evolve through processes such as displacement, layering, drift, conversion, and exhaustion [50,52]. For our purposes, focusing on evolving proximity policy, we considered the displacement process. Displacement implies that established understandings or actions can be pushed aside by existing but subordinate understandings and measures, allowing the reinterpretation or rediscovery of certain policies. In the present case, this means that the ways proximity is contextualized and problematized, and potentially measured and implemented [53,54], are complemented by the experiences of planners other than transport and land-use professionals, for example from the fields of healthcare, social care, and school planning. Such complementation permits a more holistic understanding, and is optimally created by knowledge exchange between actors from different disciplines (cf. Reference [55]).

\section{Materials and Methods}

To explore the aim and research questions of this study, we investigated how professional planners understand issues of sustainable accessibility in general, and proximity-oriented planning in 
particular. In the form of workshops, we conducted six semi-structured focus-group interviews with municipal planners. Two consecutive workshops were held in each of three municipalities located in the Västra Götaland region of Sweden. A brief methodological description follows. For a more detailed description, see Gil Solá et al. [26].

The selected municipalities were Gothenburg, considered a larger Swedish city (565,000 inhabitants), and two medium-sized cities, Mölndal (67,000 inhabitants), located within the Gothenburg urban region, and Uddevalla (56,000 inhabitants), located about $80 \mathrm{~km}$ away [56]. These municipalities represent different geographical settings. Although the municipalities of Mölndal and Uddevalla contain mixed urban and rural settings, the selection created a risk of overemphasizing urbanoriented problems.

With help from a contact person in each municipality, we selected participants from different sectors, such as the transport, land-use, care, education, and cultural sectors (see Table 1, showing the planning sectors represented). The selection was guided by the understanding that issues of accessibility and geographic proximity are important across various municipal administrations, and that planners from different sectors have important and complementary experiences with addressing these issues. Our aim was to encourage knowledge exchange between planners from different disciplines, as well as between planners and researchers, leading to new co-created knowledge [55,57]. In total, 10-14 people attended each workshop.

Table 1. Number of participants and participating sectors in each municipality.

\begin{tabular}{ccl}
\hline Municipality & No. of Participants & \multicolumn{1}{c}{ Planning Sectors Represented } \\
\hline Gothenburg & 10 & $\begin{array}{l}\text { Sustainable transport, real estate, senior citizens, public health, } \\
\text { leisure, parks, environment, social, transport, traffic, and } \\
\text { strategic land-use planning }\end{array}$ \\
\hline Mölndal & 11 & $\begin{array}{l}\text { Senior citizens, transport, traffic, comprehensive planning, } \\
\text { public health, education, leisure, and environment }\end{array}$ \\
\hline Uddevalla & 14 & $\begin{array}{l}\text { Environment, real estate, business, children, education, energy, } \\
\text { strategic planning, traffic, public transit, comprehensive } \\
\text { planning, culture, and leisure }\end{array}$ \\
\hline
\end{tabular}

For each municipality, our analysis drew on data from five exercises conducted in two consecutive workshops (see Figure 1, showing the organization of data collection). The whole process was documented on a whiteboard in each workshop. The workshops intentionally used a semi-structured design, allowing for discussion and reflection in order to capture the participants' interpretations. A pre-workshop survey was sent to the participants via e-mail, in order to obtain information about the participants (exercise 1 in Figure 1). The first exercise of workshop I (exercise 2 in Figure 1) was an introductory, moderated roundtable presentation to recount the most important current planning problems handled by the participants. This was followed by a semi-structured, moderated group exercise focusing on the services and amenities considered the most important to have located near citizens' places of residence (exercise 3 in Figure 1). Participants started discussing the matter in pairs with the aid of a figure showing a house surrounded by two circles representing distances of 10 and $30 \mathrm{~min}$. After approximately $10 \mathrm{~min}$, a group conversation followed, allowing for discussion and questioning. The researchers wrote all the responses on the whiteboard, serving as joint memory of what was said. This procedure was followed by a moderator-led discussion of the social aspects of accessibility (exercise 4, Figure 1). Between the workshops, the researchers summarized and classified the responses from the proximity exercise, and the resulting chart was used to introduce the second workshop. The second workshop proceeded with a semi-structured group exercise in which each group was asked to formulate local goals for sustainable accessibility (exercise 5, Figure 1). 


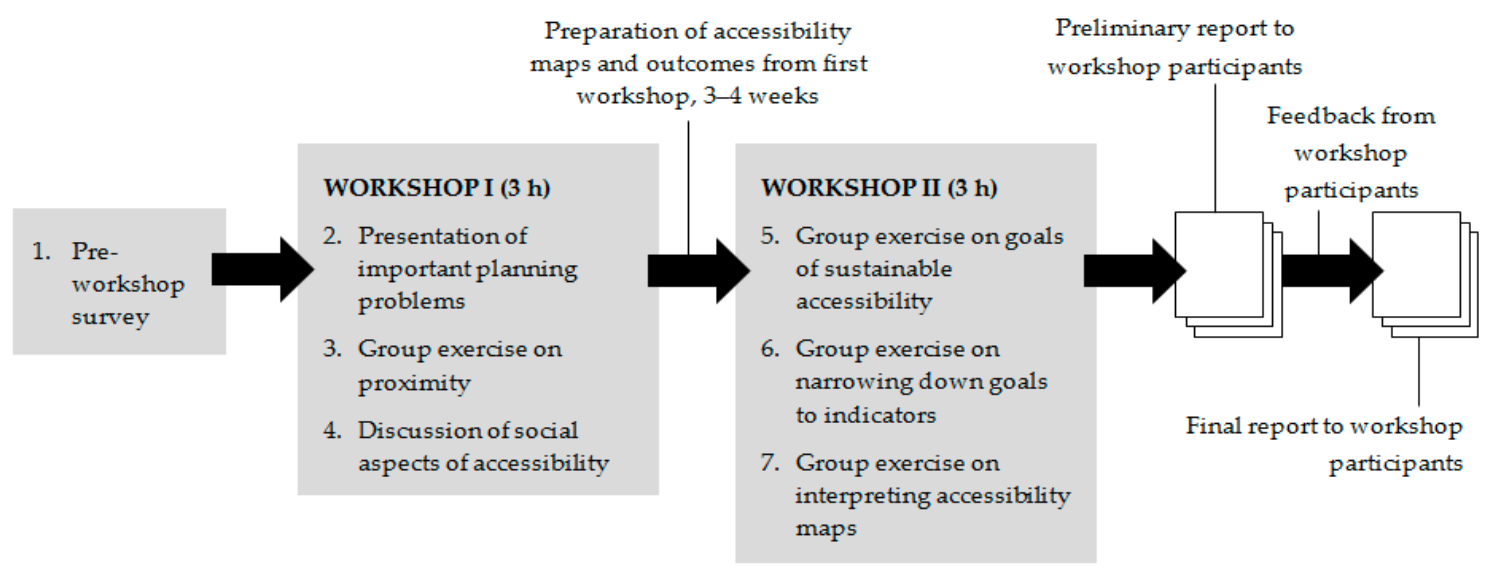

Figure 1. Schematic of data collection and interaction with participants [26].

The present analysis is based on data collected in these exercises, more precisely on transcriptions of the recorded discussions and on images of whiteboard notes from the discussions. A systematic thematic analysis was undertaken by one researcher and discussed with the co-author several times during the analytical process. The analysis started by crystallizing the illustrative model (later called "the Flower"), the analytical method being developed jointly with workshop participants during the workshops and discussed within the research group between workshops. The planners' different perceptions and understandings of proximity were analyzed in a second stage. Initially, the analysis was conducted by systematically searching for topics and contexts in which the concept of proximity was touched on (both explicitly and implicitly). Three main themes were identified, which were refined according to certain core aspects: (i) Central characteristics, (ii) a starting point for understanding (i.e., individual, planner, and other), (iii) scale, (iv) how social issues were raised, (v) related planning problems and solutions, as well as (vi) the contexts in which the themes were used and (vii) by whom.

For each understanding, we describe which professional group typically expressed or implied it. This does not mean that the workshop participants each related to only one understanding: On the contrary, several participants related to two or all of the understandings during the workshops. It is also important to note that the different understandings of proximity were crystallized from workshop discussions on the concept of sustainable accessibility, not the proximity concept as such. However, proximity was understood as central to the concept of sustainable accessibility by both the planners and the researchers [26].

\section{Planners' Understandings of Proximity}

In the workshop discussions, the planners revealed different ways of speaking about, specifying, and understanding the concept of proximity. These were partly associated with their different professional backgrounds, experiences, and current positions, for example regarding the specific planning issues they manage. These also affected the type of proximity-related planning problems they perceived and raised in the workshops (cf. References $[53,54]$ ). Overall, three main types of understanding emerged, the established, local community, and personal environment understandings: These are not mutually exclusive, but refer to intersecting perspectives (summarized in Table 2) and different scales (Figure 2). 
Table 2. Overview of planners' understandings of proximity.

\begin{tabular}{llll}
\hline Core Aspects & Established Understanding & \multicolumn{1}{c}{$\begin{array}{c}\text { Local Community } \\
\text { Understanding }\end{array}$} & $\begin{array}{c}\text { Personal Environment } \\
\text { Understanding }\end{array}$ \\
\hline $\begin{array}{l}\text { Central } \\
\text { characteristics of } \\
\text { understanding }\end{array}$ & $\begin{array}{l}\text { Proximity seen as important } \\
\text { for a functioning everyday life, } \\
\text { a focus on localization of } \\
\text { destinations or activities and } \\
\text { transport }\end{array}$ & $\begin{array}{l}\text { Focus on relationships within } \\
\text { neighborhoods, accessible } \\
\text { meeting places near } \\
\text { residences, importance of } \\
\text { walking and biking }\end{array}$ & $\begin{array}{l}\text { Local barriers seen as } \\
\text { critical for an individual's } \\
\text { access to the wider } \\
\text { environment }\end{array}$ \\
\hline Focal entity & $\begin{array}{l}\text { Inclusive urban structures } \\
\text { facilitating sustainable } \\
\text { everyday life }\end{array}$ & $\begin{array}{l}\text { Individuals and residential } \\
\text { areas }\end{array}$ & $\begin{array}{l}\text { Individuals' mobility in } \\
\text { the home and out of the } \\
\text { home }\end{array}$ \\
\hline $\begin{array}{l}\text { Typically } \\
\text { represented by }\end{array}$ & $\begin{array}{l}\text { Strategic comprehensive } \\
\text { planning, traffic and } \\
\text { infrastructure planning, } \\
\text { property management }\end{array}$ & $\begin{array}{l}\text { Planners of social services, } \\
\text { parks and nature, public } \\
\text { health, elderly care }\end{array}$ & $\begin{array}{l}\text { Planners of social services, } \\
\text { public health, elderly care }\end{array}$ \\
\hline $\begin{array}{l}\text { Social issues } \\
\text { raised }\end{array}$ & $\begin{array}{l}\text { Social and spatial distribution } \\
\text { important from overall } \\
\text { welfare perspective }\end{array}$ & $\begin{array}{l}\text { Social interaction in } \\
\text { neighborhoods, local } \\
\text { community participation, } \\
\text { health and quality of life }\end{array}$ & $\begin{array}{l}\text { Participation in society at } \\
\text { all levels }\end{array}$ \\
\hline Scale focus & Regional level & Local level (neighborhood) & $\begin{array}{l}\text { Closest physical } \\
\text { surroundings }\end{array}$ \\
\hline
\end{tabular}

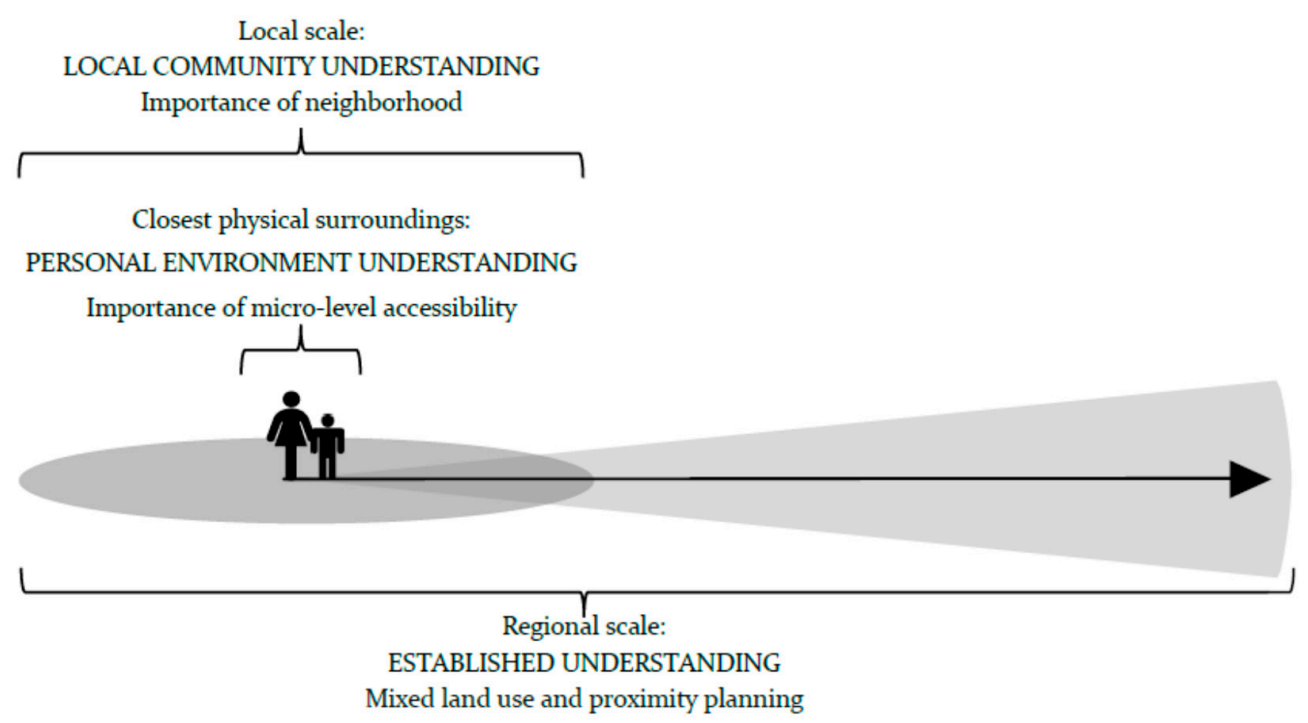

Figure 2. Relationship between the three understandings: Geographical scale and spatial focus.

\subsection{The Established Understanding: Planning for Mixed Land Use and Proximity from Above}

The established understanding of proximity concerns comprehensive urban planning and a higher, urban scale. It starts from an understanding based on the perspectives of long-established planning professions (e.g., architects, traffic engineers, and real estate or land-use managers). During the workshops, this understanding of proximity-although reflective and in a process of transformationwas mainly represented by professionals from the departments of strategic comprehensive planning, traffic planning, infrastructure planning, and land-use or property management. It was also the dominant, or mainstream, understanding, with the others serving more as counterpoints.

Basically, the established understanding treats proximity as important for a functioning everyday life in a sustainable urban setting. It addresses issues concerning the activities and services people need to have nearby to facilitate everyday life, and considers appropriate location strategies, simply stated, as creating proximity by either adding services where people already live or building more homes where there is already a good service supply. A typical expression of this understanding in the workshops 
highlighted thoughts about the local destinations or activities that various resident groups lack to be able to live efficient daily lives without using a car, and applied a traffic engineer's perspective:

... Similarly, deficiencies in content [may] be an accessibility issue-what is available in the city or in the projected environment, and what is missing. This might be destinations of interest, commercial establishments, or meeting places. It could actually be an analysis of the whole picture ... There is also the matter of links ... to public transport stops-that is, analyses of deficiencies in links ... to points from which you then continue on farther. Wherever you are going. (Land-use planner, Mölndal)

Within the framework of established urban policy and planning, this understanding of proximity has become central when formulating and implementing goals regarding sustainable accessibility $[26,37,39]$. Proximity is to be achieved through densifying the city, mixing activities and land use, and shifting to sustainable transportation modes: Well-functioning walking, cycling, and public transport. This reflects a reorientation of discourse found in politically determined visions, goals, policy documents, and planning guidelines, such as the Gothenburg City Traffic Strategy [20].

In this understanding, the social dimension is present in terms of social and spatial distributions seen from an overall, aggregated welfare perspective on equality: Striving for fairness through creating proximity to important activities in everyday life is an important goal. This relates to a long-established and all-embracing norm of the Swedish welfare state (cf. Reference [26]). Geographic proximity is then considered particularly important for groups that are immobile, lack access to a car, or need proximity for other reasons. These groups may need greater proximity to specific amenities:

... Social sustainability then ... We want a community in which basic human needs are met. That means different things for different groups in different areas. This is actually not an equality issue as such ... It may happen that in some particular area a district healthcare center need not be located within 15 minutes' travel distance, but for a million program [low income housing] area such proximity could be extremely important, given that there is more ill-health there. Health is a basic human need that must be met. It could also be that neighborhood athletic facilities for sports activities typically engaged in outside the home should be much larger in some areas than in others, given that this need is being met in other ways in other areas. (Real estate planner, Uddevalla)

A well-functioning neighborhood should meet and satisfy people's basic needs in their daily lives, and empower vulnerable groups. Because proximity cannot be created throughout a municipality, remote areas located far from local centers will by definition have poor access to concentrated services and activities. Spatial inequality is therefore also linked to the ability of different groups to settle in areas where proximity (through walking and biking) can serve as the main individual accessibility strategy. For example, a mismatch occurs when old people living in houses located in less-in-demand peripheral parts of the municipality can no longer cope well there, but cannot afford to buy or rent centrally located apartments in in-demand areas due to high housing prices. This means that densification can in fact result in increased proximity for economically strong groups, but more and longer travel for those who cannot choose to live in these dense areas [28]:

There are people who have lived there for generations-They live in some dilapidated old house and they don't get much when they sell it. There are no cheap apartments in the city to move into. They would like to move downtown and be close to public services, but they don't have the financial means to make the move. (Planner, Mölndal)

The established understanding also emphasizes that people often have bonds to several "neighborhoods" enabling access such as the areas around their dwelling, their workplace, and a shopping center. Proximity needs can also be met between activities, for example when a preschool and grocery store are both located on the road between work and home, or when activities are co-located. 
This means that the conditions for proximity seen from an individual's perspective should be assessed from the perspectives of several geographical nodes or base locations. Accordingly, this approach tends to focus on more mobile groups, and on accessibility driven by transportation and the movement of people.

Participants representing the established understanding stressed the need for assessment in their work (in contrast to the understandings discussed below). The issue of what dimension of proximity is relevant to consider and measure (i.e., spatial, temporal, or perceived proximity) is then central, particularly when modes of transport are discussed. As different transport modes have different speeds and distance-bridging capabilities, the chosen dimension becomes critical in actual planning, for instance, when realizing general policy goals of increased proximity and specifying indicators and measurements.

In summary, in the established understanding, planners revealed a perception of proximity and of what should be near that treats nearness as contextual (i.e., differing among groups with different needs and constraints), multidimensional (i.e., able to be estimated as spatial, temporal, or perceived), and relational (i.e., should be estimated from several geographical nodes or base locations).

\subsection{The Local Community Understanding: The Importance of Neighborhoods}

What we here call the planners' local community understanding of proximity emphasizes residents' interactions in their neighborhoods (i.e., aspects central to socially sustainable communities) [43]. The neighborhood is seen as important for all groups, particularly those who cannot travel far (e.g., older people, children, and the carless) or who for various reasons do not want to do so. This perspective focuses on the local scale, and was often highlighted by professionals from other areas than traditional land-use and traffic planning such as planners of social services, parks and nature, public health, and elderly care. A typical quotation illustrating this understanding stressed accessible meeting places located near residences, considering them crucial for health and quality of life:

... If you are single and on a low income, or you are a senior or a child, you are often limited to a fairly ... well, you can't go very far, so your neighborhood is particularly important. There should be green spaces there, places to sit down and rest, and places to meet up with others. I have a fantastic example: I interviewed some ladies who very much appreciated the flowerbeds. They'd go out into the courtyard and meet up at this flowerbed and watch the changing of the seasons. Their little get-togethers had beneficial effects-They got exercise that helped them maintain their balance and kept them active, and they had a routine and enjoyed social interaction. There were so many values linked to this flowerbed. So we said, 'Don't take it away. Keep it!'. And that was also a form of access to meeting places and social contact. So the neighborhood is important, I think. (Public health planner, Mölndal)

The planners also emphasized that social context extends beyond a specific physical location and current situation, encompassing, for instance, the opportunity to participate in society, develop local ties, and be able to recognize neighbors. The time perspective then becomes important, because social relationships and trust often take time to build and maintain:

... Feeling that you're part of what's happening around you doesn't have to mean participating in civic discussions. There is value in knowing what the neighbors are doing, interacting with them when you take out the trash. Just being able to go out and exchange a few words with the neighbors at all may be valuable for someone who rarely gets out. It can help you feel like you're part of a community. So this applies from the small things in life to the big ones ... (Planner, Gothenburg)

The social context is perceived to be strengthened when many people move about in public space and frequently see and meet each other spontaneously. A traffic planner saw this as a positive side effect of reducing car-based trips, and as integral to a planning strategy: 
... It's a form of social sustainability: If you have a community in which many people can get to places without a car, within a certain radius, somehow that will mean that many people are out and moving around. Without a car, but cycling and walking. [One sees] faces $\ldots$ and that in itself can create a form of social sustainability. (Transport planner, Mölndal)

Although walkability and walkable neighborhoods were not always explicitly mentioned in these discussions, the local community understanding clearly invoked New Urbanism ideals [58] and theories of social capital [45] when relating the use of local areas to the development of social ties and trust. The important role of nearby-located activities that residents could walk to and where they could meet, making proximity to everyday activities a basis for developing and strengthening the social context, was also implicit (cf. References [43,58]).

From a planning perspective, traditional land-use planners are recognized as lacking sufficient knowledge of residents' social ties, specific wants, and needs. A planner from Uddevalla described this when emphasizing the lack of knowledge in central administration of residents' perceptions of an area:

We [planners] may not be representative of, say, the people living in these million program [low income housing] areas such as in the northern suburbs of Uddevalla. And I know and believe that while not everyone wants to live there, many people do. They don't want to live in a fancy new riverside neighborhood just because we planners want them to and think everyone wants to. They like it where they live. They feel safe there and they really like their neighborhood. And it's a huge waste of resources to believe that everyone wants to move out of an area where a lot of people live. If we were to build a new apartment building up there and have it completed by tomorrow, it would be full because a lot of people do want to live up there. I feel the same way you [i.e., fellow workshop participant] do, that actually we need to improve an area like this. Invest in features that improve the place where they live, the place where many people actually want to live. (Real estate planner, Uddevalla)

Consequently, this understanding shifts attention in the planning process from the central municipal administration to local administration, underlining the importance of decentralized planning that stresses interaction with citizens. Planners from Gothenburg cited the work of local district administrations (Stadsdelsförvaltningar in Gothenburg) as an example, particularly concerning communication and dialogue with citizens when specifying central policy goals about "well-functioning neighborhoods". The Gothenburg planners believed that officials at these local district administrations often have a deeper, more nuanced understanding of citizens' needs and wishes than is found in the central administration. A decentralized management structure was regarded as enabling ongoing dialogue with residents, qualitatively different from centrally initiated citizen dialogue concerning specific projects (e.g., major infrastructure investments).

But in that sense the municipal district administration is a good resource, because they often have in-depth knowledge and are in touch with local organizations and civically engaged residents. The district administration can help you get an idea of what people in a particular neighborhood want. (Planner, Gothenburg)

Comparing the local community and established understandings, the established understanding is more directed toward the involvement of actors inside and outside the municipal organization, such as property owners, developers, and builders. In contrast, the local community understanding primarily concerns citizens' views and needs, and potential conflicts between different groups of residents.

\subsection{The Personal Environment Understanding: The Microlevel Makes a Difference}

The personal environment understanding of proximity concerns the individual's immediate physical surroundings at a very detailed scale. The understanding typically refers to less physically mobile people such as small children or the disabled elderly. Barriers in the proximate environment, such as going down stairs or boarding buses, are seen as crucial for individuals' access to the wider 
environment and to quality of life. This understanding stresses aspects of the environment giving rise to physical and psychological barriers that preclude vulnerable groups from using the transport system and, ultimately, participating in society [32]. It refers to microlevel accessibility, also related to the potential for access locally and regionally [59]. This understanding is central to planners active in social services, elderly care, and health services. Typical articulations based on the personal environment understanding highlighted, for example, the physical barriers elderly people face when walking on the street:

In the winter it should be possible to use this walkway. Sometimes you have to be able to get over the piles of snow left by the snow plow. That's what my 80 -year-olds say. That they don't get out after the snow plow has left its piles [of ice and snow]. Sometimes they can't cross the street or even get out of their buildings. Snow clearance creates accessibility for cars, but not for pedestrians. (Senior citizen planner, Mölndal)

However, the personal environment perspective does not necessarily target vulnerable groups, and traffic planners agreed that "entirely mobile" groups were often emphasized when identifying barriers in the immediate vicinity. Such barriers, though small, are important because they affect local and regional accessibility. Typical planning strategies related to the personal environment concentrate on the lowest level of scale in community planning, such as the supply of facilities near housing or missing links in a bike lane network, which can be crucial for a functioning everyday life:

...We're in the process of implementing a system of on-site waste collection-that is, for single-family dwellings-with recycling containers placed right on your lot. Which is, I think, a great example of accessibility in line with our environmental and climate goals. (Sustainable mobility planner, Mölndal)

I think that [bike lanes] should be a standard part of any street. There shouldn't be missing links. The route should start right from the building. (Planner, Mölndal)

Of the three understandings of proximity identified and discussed here, the personal environment understanding was the least dominant during the workshops.

\section{Planners Negotiating Proximity: Developing an Integrative Tool}

The study's second research question concerned how a joint understanding of proximity could be supported and molded by various professional perspectives, conceptions, and interests. During the workshops, we tested a tool that could be used as a basis for integrative dialogue. The workshop discussions of the tool are described here and then analyzed in relation to the three understandings in the concluding discussion.

\subsection{Proximity to What: Planners' Appraisals of Citizens' Needs}

The first workshop included an exercise addressing planners' professional opinions on what activities and amenities citizens need to have near their homes. The basis for discussion was a simple map showing a home at the center of two circles, indicating time distances of 10 and $30 \mathrm{~min}$.

As an outcome example, the assessments conducted by participants from Gothenburg are summarized in Figure 3. The chart, a flower-like illustrative model, shows what was considered important to have immediately adjacent to the home, within $10 \mathrm{~min}$ and within 10-30 min. Various activities are clustered in the activity spheres of daily life, like petals on a flower (this clustering was done by the researchers after the workshop). In the Gothenburg example, participants considered that, for instance, bicycle or stroller parking, recycling facilities, trees, and potential activity space (e.g., for barbeques) should be located adjacent to homes. A car parking lot, public transport stop, healthcare center, convenience store, post office, daycare center and school, recreation area (e.g., soccer field), and municipal office should be located within $10 \mathrm{~min}$ distance from home. Amenities such as a hospital, university, city park, and cinema could acceptably be located farther away, within 10-30 min. 


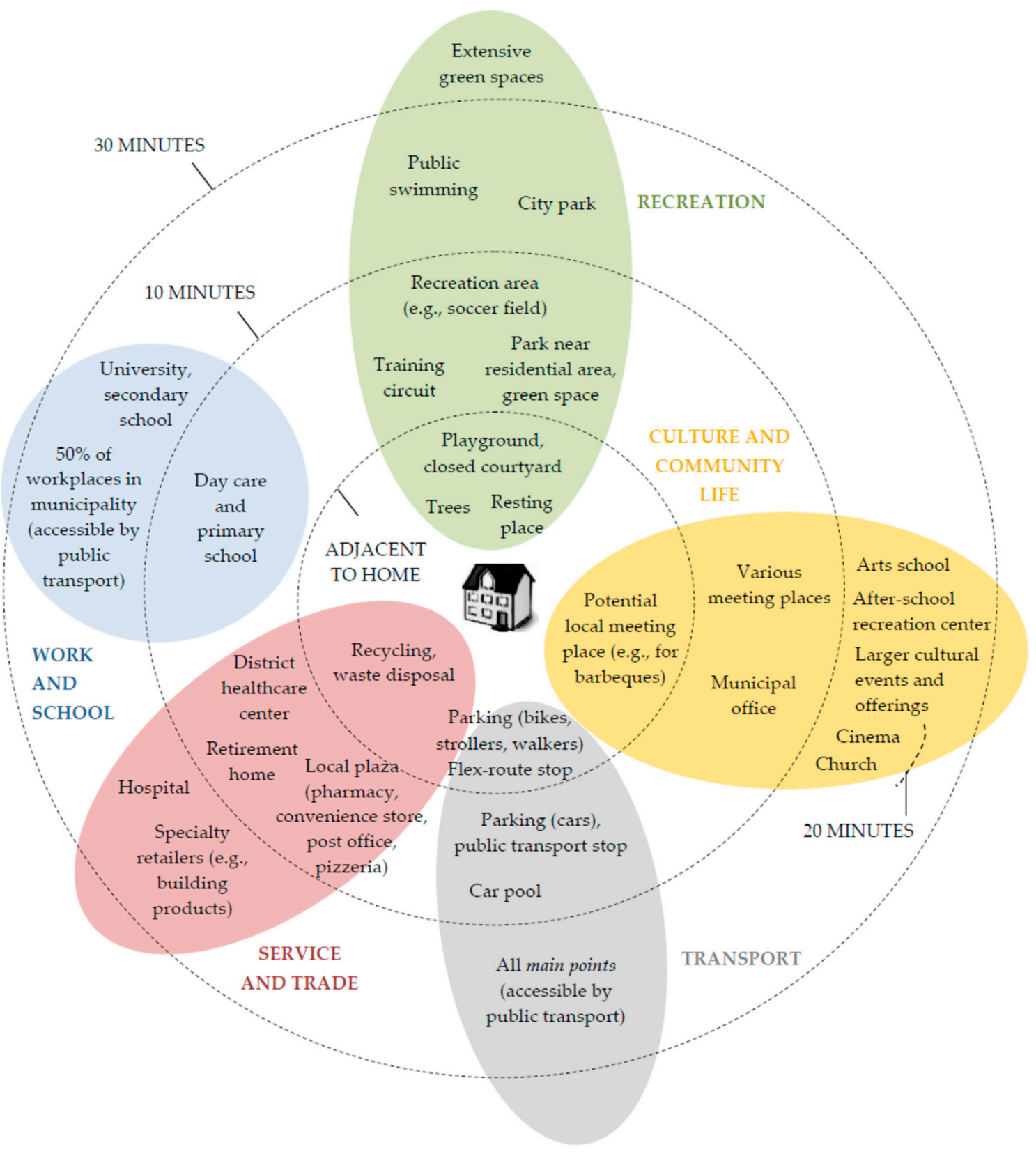

Figure 3. Categorization of Gothenburg participants' answers to the question, "In your professional opinion, what is important to have located near places of residence?". The model was called "the Flower" by participants. The term "main points" concerns central Gothenburg and six areas in the region. These are important nodes in the public transport system due to their surrounding mixed land-use areas, meant to be developed through densification [20].

In the workshop exercise, proximity was measured in terms of time, as we wanted to represent the view of proximity people normally use when scheduling everyday activities, taking constraints of time and space into consideration. We also avoided prescribing what means of travel to use to provide access (e.g., by foot or car). Consequently, an immediate question and recurring theme of discussion was what means of transport should be used to measure travel time. The main response to this was that activities central to daily needs and routines should be reachable within $10 \mathrm{~min}$ by walking or cycling from the home. This was also in line with current municipal goals of accessibility in the planning documents of, for example, Gothenburg [20]. 


\subsection{The Proximity Exercise and the Flower as a Planning Tool}

The discussion following the proximity exercise and the formulation of the illustrative modelcalled "the Flower" by participants-showed that the model could serve as a basis for wider dialogue between actors. According to participants, one strength of the exercise was that it linked values traditionally associated with separate municipal planning domains. The exercise also addressed the everyday context and lives of the city's inhabitants. It problematized the understanding of proximity and accessibility in terms of geographical distance or time, and whether it was perceived objectively or subjectively. This was done in a relatively simple and inclusive way that could facilitate dialogue between various actors, for example between planners and citizens, politicians, business representatives, and NGOs.

The planners in Mölndal, for example, described the exercise as a good tool for use in citizen dialogues, not least because of its simplicity and use of shared language. These planners also discussed whether it could be used in dialogue between different municipal administrations:

I think this type of model would be of great benefit to us, as it would give us a language for talking about the value of the neighborhood and focusing on the local community. We don't speak in those terms, but rather in terms of premises planning and efficient premises ... From that point of view, we prioritize the efficient use of premises. But if that has effects, such as weakening social cohesion, requiring children to walk longer distances, breaking up other social structures, or making things worse for seniors, we don't currently bring that dimension into our planning process. We don't have any opportunity for that discussion to take place-We don't accommodate it. I don't feel we have a structure to enable us to talk that way, but rather that our discussions focus on each individual process separately. (Land-use planner, Mölndal)

Participants also believed that the model could provide a basis for discussing the potential consequences of various planning alternatives and measures for the municipality's supply of activities and services. For example, the lack of important services (e.g., elderly care or schools) in a given area could entail greater municipal travel costs for social transport services or school shuttles. Responsibility for managing such side effects often lies in other sectors of the municipal administration than the city-building office, where many localization decisions are made. "The Flower" model, and the process of specifying accessibility to what and for whom, could serve as a platform for ongoing discussions of consequences and alternative costs. However, it was evident that if the model and process is to be used for such a purpose, more concrete planning cases should be used. Participating planners also suggested that "the Flower" model process could be used as a checklist and provide support when developing detailed development plans.

\section{Conclusions}

In this article we examined urban planners' experiences and understandings of proximity-oriented policies to foster urban sustainability. We investigated the views of professionals representing a broad spectrum of municipal administrations and sectors, ranging from transport and comprehensive land use, to healthcare, green areas and parks, schools and daycare, retail, services, and leisure activities. We intended to uncover potentials and tensions emerging when the concept is put into practice. Furthermore, we explored a tentative tool, activating reflection and conversation between the planners, for establishing common ground when proximity goals are to be used in concrete planning and implementation. By elucidating different understandings of proximity, and how proximity can be implemented as a planning goal, our study contributes to a more integrative proximity-oriented planning, as well as to the limited literature on planners' understandings of proximity in the context of the transition from mobility-enhancing to accessibility-oriented strategies for sustainable urban planning. 
Overall, the planners viewed proximity to daily activities as central to individuals' well-being and to increasing urban sustainability. A basic distinction was recurrently made between temporal proximity (enabled by fast transport) and geographical proximity (enabled by near location and mixed land use). Temporal proximity (or nearness in time), traditionally associated with planning for cars, is considered important so that everyday life can function smoothly and effortlessly. Enabling geographical proximity (or nearness in space), on the other hand, is perceived as crucial to achieving sustainable urban life and mobility, for example by supporting measures promoting urban densification, mixed land use, and walking and cycling. It is also traditionally regarded as an important accessibility strategy for vulnerable groups, mainly people having difficulties traveling longer distances, predominantly small children, elderly, and disabled people. Proximity is thus seen as a constituent of both ecologically and socially sustainable city planning.

The results also revealed divergent understandings of proximity, highlighting the contested nature of proximity as a planning goal. Divergent opinions concerned objects and subjects, scale levels, planning problems, and potential measures and solutions. Proximity was negotiated according to three basic understandings: First, the established understanding of transportation and land-use integration, relying on planners' expert views of how to influence the overall regional spatial distribution of amenities and population, and the interactions between places; second, the local community understanding, emphasizing the social context of neighborhoods and the relationships within places; and third, the personal environment understanding, centering on individuals' interactions with immediate physical space at a very detailed level.

The three understandings both contrast with and overlap one another, linking the regional to the local and personal levels of urban space. These understandings are also associated with somewhat divergent conceptions of what is being planned for and what planning entities are involved. The established understanding of proximity clearly relates to locational issues and objects, for example where to locate services, residential areas, and transportation infrastructures. It emphasizes patterns of transferability and potential between local areas. The local community understanding focuses distinctly on the role of internal relationships and attachments between people and their places of residence, the role of local community participation, and how to create attractive, safe, and healthy neighborhoods. It emphasizes the importance of socially sustainable communities [43]. The personal environment understanding relates to barriers and hindered access encountered not only by people with reduced mobility function and disability in particular, but also by fully functional groups (cf. References [41,59]). The observed views are also largely associated with differences in professional attitude and planning experience between regional land-use and transportation planning traditionally rooted in expert (i.e., engineering) modeling and planning "from above", and local and personal space-oriented views relying more on social participatory planning ideals and practices. Our analysis shows that proximity goals can be contextualized in different ways, relating to different problems. In the context of urban and regional planning, this is of fundamental concern, as how problems are framed and understood affect how they are solved [53,54].

Although distinct differences are found between the three understandings, there is clear interconnectedness and complementarity between them. Arguably, the dominant established understanding is enriched by the local community and personal environment understandings. There also is interdependence between the established and community understandings when it comes to implementation, such a relationship being central to current ideals and theories such as New Urbanism (cf. Reference [58]) and Social Capital (cf. References [3,4,45]): The regular use of activities in an area allows the development of relationships with local inhabitants and specific places [48], establishing a basis for a sense of local community. The reverse also holds, and residents experiencing a place as positive are more likely to use everyday activities located there, instead of traveling farther away [47]. When shifting to a planning paradigm of proximity, planners should therefore concentrate on both offering various needed activities at the local level and improving opportunities for social interaction between community residents, thereby creating healthy and safe environments and a sense of place 
(cf. Reference [58]). This means that proximity planning policy should more fully take into account the experience of social planners, understanding the needs of residents at a different level from that of the more engineering-oriented land-use and transportation planners.

This study highlighted how emerging proximity-oriented planning can go beyond the dominant understanding of land-use and transport planners, by integrating complementary contextualizations, thereby developing proximity policy and goals through a process of drift [50,52]. To aid such integration, we tentatively developed and tested a collaborative planning exercise. The resulting tool, referred to as "the Flower" model by the participating planners, concerned the importance of nearness and the specific activities citizens need to have nearby in daily life. Because of its simplicity, and the fact that it links values and norms traditionally related to different municipal planning domains, the participants thought that it had good potential to improve communication between stakeholders. However, the model mainly relates to the established understanding, as well as to the personal environment understanding, due to its land-use and location focus. To fully integrate the different understandings of proximity presented here, the tool must be improved to better incorporate central aspects of the local community understanding. Within the frame of the exercise, this could be addressed by discussing with residents what makes them thrive in their neighborhood, as well as the specific qualities of activities to be located in their neighborhood (cf. Reference [26]). It is also about planning dedicated public spaces to be freely used by residents, as well as understanding what type of informal public spaces residents want to use, develop, and control.

A case study based on three focus-group workshops with 35 planners, such as this, has some limits to generalizability. The results are context-bound and affected by specific conditions. The study was conducted in a relatively urbanized Swedish region, and the results may underestimate rural and semi-urban contexts and understandings of proximity. Notably, the study was embedded in the context of a northern European welfare state, which has implications for the organization of municipalities and policy implementation. Further, we gathered planners from many areas of expertise, allowing us to find different ways of contextualizing and relating to proximity. However, more variations might have been found if discussions were held with other combinations of planners. Furthermore, the discussions were framed as addressing problems of sustainable accessibility, which may well have affected how the concept of proximity was discussed. These limitations all suggest directions for future studies, which should examine proximity in other contexts and with other groups of professionals, to identify additional experiences, understandings, and implementations.

Author Contributions: Conceptualization, A.G.S. and B.V.; data collection, A.G.S. and B.V.; primary analysis, A.G.S.; writing-original draft preparation, A.G.S. and B.V.; writing-review and editing, A.G.S.; funding acquisition, B.V. and A.G.S.

Funding: This research was funded by the Swedish Research Council Formas (project number 259-2013-103) and the Sustainable Transport Initiative of the University of Gothenburg and Chalmers University of Technology.

Acknowledgments: The authors express their gratitude to Thomas Straatemeier at Goudappel Coffeng (The Netherlands) for introducing them to the model used as a basis for discussions with planners and later on developed into the Flower model. We thank Anders Larsson at the University of Gothenburg for his cooperation regarding funding acquisition and data collection. We would also like to thank the participating municipalities and planners for taking the time to share their valuable knowledge and experiences, as well as the Mobility Research Group at the University of Gothenburg for their constructive comments on an early draft of this paper.

Conflicts of Interest: The authors declare no conflicts of interest.

\section{References}

1. Banister, D.; Anable, J. Transport policies and climate change. In Planning for Climate Change: Strategies for Mitigation and Adaptation for Spatial Planners; Davoudi, S., Crawford, J., Eds.; Earthscan: London, UK, 2009; pp. 55-69.

2. Davoudi, S.; Hall, S.P.; Power, A. Key issues for planning futures and the way forward. Twenty-First Century Soc. 2008, 3, 229-247. [CrossRef] 
3. David, Q.; Janiak, A.; Wasmer, E. Local social capital and geographical mobility. J. Urban Econ. 2010, 68, 191-204. [CrossRef]

4. Kintrea, K. Social mix: International policy approaches. In Neighbourhood Effects or Neighbourhood Based Problems?: A Policy Context; Manley, D., Van Ham, M., Bailey, N., Simpson, L., Maclennan, D., Eds.; Springer: Dordrecht, The Netherlands, 2013; pp. 133-155.

5. Boschma, R. Proximity and innovation: A critical assessment. Reg. Stud. 2005, 39, 61-74. [CrossRef]

6. Hansen, T. Substitution or overlap? The relationship between geographical and non-spatial proximity dimensions in collaborative innovation projects. Reg. Stud. 2015, 49, 1672-1684. [CrossRef]

7. Cervero, R. Balanced Transport and Sustainable Urbanism: Enhancing Mobility and Accessibility Through Institutional, Demand Management, and Land-Use Initiatives. Urban Plan. Overseas 2005, 20, 15-27.

8. Handy, S. Accessibility- vs. Mobility-Enhancing Strategies for Addressing Automobile Dependence in the U.S. Prepared for the European Conference of Ministers of Transport. 2002. Available online: http: / / www.escholarship.org/uc/item/5kn4s4pb.pdf;origin=repeccitec (accessed on 31 October 2018).

9. Banister, D. The sustainable mobility paradigm. Transp. Policy 2008, 15, 73-80. [CrossRef]

10. Curtis, C. Planning for sustainable accessibility: The implementation challenge. Transp. Policy 2008, 15, 104-112. [CrossRef]

11. UN Habitat. Planning and Design for Sustainable Urban Mobility; Global Report on Human Settlements; Routledge: New York, NY, USA, 2013.

12. Bertolini, L.; le Clercq, F.; Kapoen, L. Sustainable accessibility: A conceptual framework to integrate transport and land use plan-making. Two test-applications in the Netherlands and a reflection on the way forward. Transp. Policy 2005, 12, 207-220. [CrossRef]

13. Johansson, H.; Sandvik, K.O.; Zsidákovits, J.; Lutcyk, G. A need for new methods in the paradigm shift from mobility to sustainable accessibility. Transp. Res. Procedia 2016, 14, 412-421. [CrossRef]

14. Van Wee, B. Accessible accessibility research challenges. J. Transp. Geogr. 2016, 51, 9-16. [CrossRef]

15. Qviström, M. Putting accessibility in place: A relational reading of accessibility in policies for transit-oriented development. Geoforum 2015, 58, 166-173. [CrossRef]

16. Levinson, D.; Gillen, D. The machine for access. In Access to Destinations; Levinson, D., Krizek, K., Eds.; Elsevier: Oxford, UK, 2005.

17. Halden, D. The use and abuse of accessibility measures in UK passenger transport planning. Res. Transp. Bus. Manag. 2011, 2, 12-19. [CrossRef]

18. Proffitt, D.; Bartholomew, K.; Ewing, R.; Miller, H. Accessibility planning in American metropolitan areas: Are we there yet? In Proceedings of the Transportation Research Board 94th Annual Meeting, Washington, DC, USA, 11-15 January 2015.

19. Stockholmregionen. En Närmare Stad; Tillväxt- och Regionplaneförvaltningen: Stockholm, Sweden, 2015.

20. City of Gothenburg. Gothenburg 2035: Transport Strategy for a Close-Knit City; City of Gothenburg: Gothenburg, Sweden, 2014.

21. Malmö City. Sustainable Urban Mobility Plan: Creating a More Accessible Malmö; Malmö City: Malmö, Sweden, 2016.

22. Katrineholms Kommun. Översiktsplan 2030. Del Staden; Katrineholms Kommun: Katrineholm, Sweden, 2015.

23. Uppsala Kommun. Översiktsplan 2016 för Uppsala Kommun; Uppsala Kommun: Uppsala, Sweden, 2016.

24. Peck, J. Geographies of policy: From transfer diffusion to mobility-mutation. Prog. Hum. Geogr. 2011, 35, 773-797. [CrossRef]

25. EU Commision. Planning for People. Guidelines. Developing and Implementing a Sustainable Urban Mobility Plan; European Commission, Directorate-General for Mobility and Transport: Brussels, Belgium, 2013.

26. Gil Solá, A.; Vilhelmson, B.; Larsson, A. Understanding sustainable accessibility in urban planning: Themes of consensus, themes of tension. J. Transp. Geogr. 2018, 70, 1-10. [CrossRef]

27. De Jong, M.; Joss, S.; Schraven, D.; Zhan, C.; Weijnen, M. Sustainable-smart-resilient-low carbon-ecoknowledge cities: Making sense of a multitude of concepts promoting sustainable urbanization. J. Clean. Prod. 2015, 109, 25-38. [CrossRef]

28. Elldér, E.; Larsson, A.; Gil Solá, A.; Vilhelmson, B. Proximity changes to what and for whom? Investigating sustainable accessibility change in the Gothenburg city region 1990-2014. Int. J. Sustain. Transp. 2018, 12, 271-285. [CrossRef] 
29. Hysing, E. Greening transport: Explaining urban transport policy change. J. Environ. Policy Plan. 2009, 11, 243-261. [CrossRef]

30. Curl, A.; Nelson, J.D.; Anable, J. Does Accessibility Planning address what matters? A review of current practice and practitioner perspectives. Res. Transp. Bus. Manag. 2011, 2, 3-11. [CrossRef]

31. Straatemeier, T.; Bertolini, L. Joint Accessibility Design. Framework Developed with Practitioners to Integrate Land Use and Transport Planning in the Netherlands. Transp. Res. Rec. 2008, 2077, 1-8. [CrossRef]

32. Church, A.; Frost, M.; Sullivan, K. Transport and social exclusion in London. Transp. Policy 2000, 7, $195-205$. [CrossRef]

33. Haugen, K. The Accessibility Paradox: Everyday Geographies of Proximity, Distance and Mobility. Ph.D. Thesis, Umeå Universiy, Umeå, Sweden, 2012.

34. Haugen, K. The advantage of "near": Which accessibilities matter to whom? EIJTIR 2011, 11, 368-388.

35. Haugen, K.; Holm, E.; Strömgren, M.; Vilhelmson, B.; Westin, K. Proximity, accessibility, and choice: A matter of taste or condition? Pap. Reg. Sci. 2012, 91, 65-84. [CrossRef]

36. Cervero, R. Paradigm Shift: From Automobility to Accessibility Planning. Urban Futures 1997, $22,9-20$.

37. Boisjoly, G.; El-Geneidy, A.M. The insider: A planners' perspective on accessibility. J. Transp. Geogr. 2017, 64, 33-43. [CrossRef]

38. Cheng, J.Q.; Bertolini, L.; le Clercq, F. Measuring Sustainable Accessibility. Transp. Res. Rec. 2007, $2017,16-25$. [CrossRef]

39. Curtis, C.; Scheurer, J. Planning for Sustainable Accessibility: Developing tools to aid discussion and decision-making. Prog. Plan. 2010, 74, 53-106. [CrossRef]

40. Envall, P. Accessibility Planning: A Chimera? Ph.D. Thesis, University of Leeds, Leeds, UK, 2007.

41. Wennberg, H.; Ståhl, A.; Hydén, C. Implementing accessibility in municipal planning-Planners' view. J. Transp. Land Use 2009, 2, 3-21.

42. Hallgrimsdottir, B.; Wennberg, H.; Svensson, H.; Ståhl, A. Implementation of accessibility policy in municipal transport planning: Progression and regression in Sweden between 2004 and 2014. Transp. Policy 2016, 49, 196-205. [CrossRef]

43. Dempsey, N.; Bramley, G.; Power, S.; Brown, C. The Social Dimension of Sustainable Development: Defining Urban Social Sustainability. Sustain. Dev. 2011, 19, 289-300. [CrossRef]

44. Luederitz, C.; Lang, D.J.; Von Wehrden, H. A systematic review of guiding principles for sustainable urban neighborhood development. Landsc. Urban Plan. 2013, 118, 40-52. [CrossRef]

45. Leyden, K.M. Social Capital and the Built Environment: The Importance of Walkable Neighborhoods. Am. J. Public Health 2003, 93, 1546-1551. [CrossRef] [PubMed]

46. Mazumdar, S.; Learnihan, V.; Cochrane, T.; Davey, R. The built environment and social capital: A systematic review. Environ. Behav. 2018, 50, 119-158. [CrossRef]

47. Waldo, Å. Staden och Resandet. Mötet Mellan Planering och Vardagsliv; Department of Sociology, Lund University: Lund, Sweden, 2003.

48. Cedering, M. Konsekvenser av Skolnedläggningar. En Studie av Barns och Barnfamiljers Vardagsliv i Samband med Skolnedläggningar i Ydre Kommun. Ph.D. Thesis, Kulturgeografiska institutionen, Uppsala universitet, Uppsala, Sweden, 2016.

49. Lee, J.; Abbott, R. Physical activity and rural young people's sense of place. Child. Geogr. 2009, 7, $191-208$. [CrossRef]

50. Streek, W.; Thelen, K. Introduction: Institutional Change in Advanced Political Economies. In Beyond Continuity. Institutional Change in Institutional Change in Advanced Political Economies; Streek, W., Thelen, K., Eds.; Oxford University Press: Oxford, UK, 2005.

51. Bartholdsson, K. Målkonflikter—en Sund Företeelse Eller ett Olösligt Problem; Naturvårdsverket: Stockholm, Sweden, 2011.

52. Rayner, J.; Howlett, M. Introduction: Understanding integrated policy strategies and their evolution. Policy Soc. 2009, 28, 99-109. [CrossRef]

53. Bacchi, C. Why Study Problematizations? Making Politics Visible. Open J. Polit. Sci. 2012, 2, 1-8. [CrossRef]

54. Tennøy, A. Why we fail to reduce urban road traffic volumes: Does it matter how planners frame the problem? Transp. Policy 2010, 17, 216-223. [CrossRef]

55. Westberg, L.; Polk, M. The role of learning in transdisciplinarity: Moving from a normative concept to an analytical tool through a practice-based approach. Sustain. Sci. 2016, 11, 385-397. [CrossRef] 
56. Statistics Sweden. Folkmängd i Riket, län och Kommuner 31 Mars 2018 och Befolkningsförändringar 1 Januari-31 Mars 2018. Available online: https://www.scb.se/hitta-statistik/statistik-efter-amne/ befolkning/befolkningens-sammansattning/befolkningsstatistik/pong/tabell-och-diagram/kvartals--ochhalvarsstatistik--kommun-lan-och-riket/kvartal-1-2018 (accessed on 22 October 2018).

57. Polk, M. Achieving the promise of transdisciplinarity: A critical exploration of the relationship between TD research and societal problem solving. Sustain. Sci. 2014, 9, 439-451. [CrossRef]

58. Lund, H. Testing the claims of New Urbanism. Local Access, Pedestrian Travel, and Neighboring Behaviors. J. Am. Plan. Assoc. 2003, 69, 414-429. [CrossRef]

59. Jones, P.; Lucas, C. The social consequences of transport decision-making: Clarifying concepts, synthesising knowledge and assessing implications. J. Transp. Geogr. 2012, 21, 4-16. [CrossRef]

2018 by the authors. Licensee MDPI, Basel, Switzerland. This article is an open access article distributed under the terms and conditions of the Creative Commons Attribution (CC BY) license (http:// creativecommons.org/licenses/by/4.0/). 